\title{
Ю. Н. Столяров
}

Научный и издательский чентр «Наука» РАН, Москва, Россия

Российская государственная библиотека, Москва, Россия

\section{СЛУЖБЫ ИНФОРМАЦИИ ПО КУЛЬТУРЕ И ИСКУССТВУ: СОСТОЯНИЕ И ПЕРСПЕКТИВЫ. (ПО МАТЕРИАЛАМ ХІ ВСЕРОССИЙСКОЙ НАУЧНО- ПРАКТИЧЕСКОЙ КОНФЕРЕНЦИИ ЩИНФОРМАЦИОННЫЙ КОНТЕКСТ КУЛЬТУРЫ: РЕСУРСЫ, ТЕХНОЛОГИИ, СЕРВИС»)}

Аннотация: XI Всероссийская научно-практическая конференция руководителей и специалистов служб информации по культуре и искусству «Информационный контекст культуры: ресурсы, технологии, сервис», организованная совместно Российской государственной библиотекой, Российской государственной библиотекой искусств и Санкт-Петербургским государственным институтом культуры, работала 24-25 сент. 2019 г. в РГБ. В ней приняли участие более 90 представителей органов управления культурой, федеральных, центральных региональных и муниципальных библиотек, вузов и учебно-методических центров повышения квалификации, а также других учреждений сферы культуры, науки, образования, массовой информации и книготорговли из 24-х регионов Российской Федерации. Благодаря онлайн-трансляциям общая аудитория мероприятия существенно расширилась. В режиме видеосвязи в мероприятии приняли участие руководители и специалисты национальных библиотек Армении, Беларуси и Казахстана. Программа включала в себя 36 докладов и сообщений. Они прозвучали на специальном заседании «Год театра в библиотеке», круглом столе «Национальная библиотека как центр информации по культуре и искусству», секции «Информационный потенциал организаций культуры в реализации государственной культурной политики». По итогам таких конференций РГБ издает сборники материалов. Последний из них вышел в 2018 г.

Ключевые слова: XI Всероссийская научно-практическая конференция руководителей и специалистов служб информации по культуре и искусству, государственная культурная политика, национальная библиотека, центр информации по культуре и искусству. 
DOI: $10.33186 / 1027-3689-2020-3-113-122$

\section{Yury N. Stolyarov}

Science and Publishing Center "Nauka" of Russian Academy of Sciences, Moscow, Russia Russian State Library, Moscow, Russia

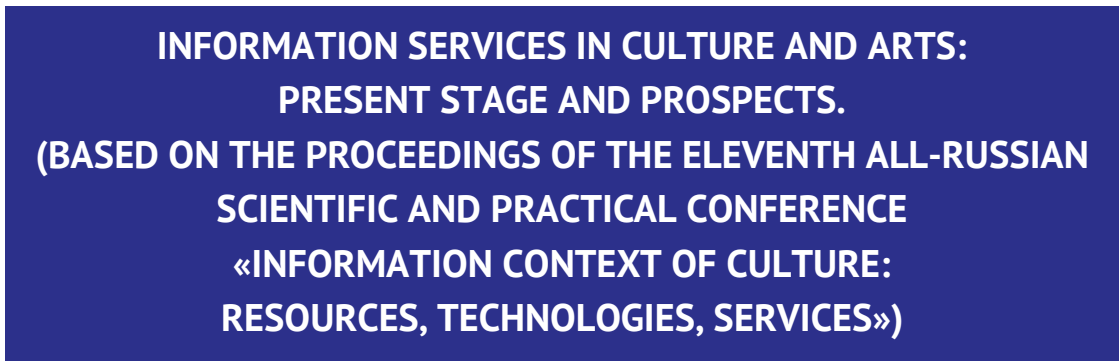

Abstract: The XI all-Russian scientific and practical conference of heads and specialists of information services on culture and art "Information context of culture: resources, technologies, service", organized by the Russian state library, the Russian state library of arts and the St. Petersburg state Institute of culture, was held in Moscow. It was attended by more than 90 representatives of the cultural authorities, Federal, Central regional and municipal libraries, universities and training centers for training, as well as other institutions of culture, science, education, media and bookselling 24 regions of the Russian Federation. Thanks to online broadcasts, the total audience of the event increased by almost 200 people. Heads and specialists of the national libraries of Armenia, Belarus and Kazakhstan took part in the event via video link. The program included 36 reports and presentations. They were presented at a special session "Year of theatre in the library", Round table" national library as a center of information on culture and art", section "Information potential of cultural organizations in the implementation of the state cultural policy". As a result of such events, the Russian state library publishes collections of materials. The last one was released in 2018.

Keywords: XI all-Russian scientific and practical conference of heads and specialists of information services on culture and art, state cultural policy, national library, cultural and art information center.

В начале 1990-х гг., когда наиболее мощная на тот момент система государственной научно-технической информации, лишившись государственной поддержки, переживала глубокий кризис, система информации в сфере культуры и искусства, напротив, приняла упорядоченный вид. 
В 1993 г. координационным центром страны в области информационного обеспечения сферы культуры стала Российская государственная библиотека. С того времени РГБ регулярно проводит всероссийские конференции (совещания) руководителей служб информации по культуре и искусству, которые функционируют при крупных библиотеках страны. Очередное такое мероприятие состоялось в РГБ (24-25 сент. 2019 г.) по инициативе РГБ, Российской государственной библиотеки искусств и Санкт-Петербургского государственного института культуры и по заданию Министерства культуры РФ.

В работе конференции приняли участие более 90 представителей органов управления культурой, федеральных, центральных региональных и муниципальных библиотек, вузов и учебно-методических центров повышения квалификации, а также других учреждений сферы культуры, науки, образования, массовой информации и книготорговли из 24 регионов Российской Федерации. Благодаря онлайн-трансляциям общая аудитория мероприятия увеличилась почти на 200 человек. В режиме видеосвязи в работе приняли участие руководители и специалисты национальных библиотек Армении, Беларуси и Казахстана. Следовательно, конференцию можно квалифицировать как всероссийскую с международным участием.

В программу конференции вошли: пленарное заседание с пятью основными докладами, специальное заседание «Год театра в библиотеке», круглый стол «Национальная библиотека как центр информации по культуре и искусству», секции «Тенденции цифровизации информационной деятельности в сфере культуры», «Информационный потенциал организаций культуры в реализации государственной культурной политики». В мероприятиях участвовали библиотекари и преподаватели из Архангельска, Губкина Белгородской области, Иркутска, Кургана, Новосибирска, Петрозаводска, Санкт-Петербурга, Ульяновска, а также представители Азербайджана (ведущий библиотекарь Национальной библиотеки А. А. Оганесян, доклад «Музей книгопечатания Национальной библиотеки Армении»), Беларуси (заместитель директора Национальной библиотеки А. А. Суша, доклад «Потребность в информации по культуре: новые тенденции в работе национальной библиотеки Беларуси»). Всего было представлено 36 докладов и сообщений. 
С докладом «Создание единого информационного пространства в сфере культуры» выступил директор Департамента информационного и цифрового развития Министерства культуры РФ В.В. Ваньков. Он проинформировал об очередном этапе создания портала «КУЛЬТУРА.РФ» и призвал к сотрудничеству в решении его основных задач: обеспечить современный и комфортный доступ к культурным благам, вызвать интерес к деятельности учреждений культуры и предоставить информацию о них для физического посещения.

Генеральный директор РГБ В. В. Дуда в докладе «Развитие электронного пространства знания в контексте реализации национального проекта "Культура"» подчеркнул: в создании такого пространства равно приоритетны документы как в нонэлектронном, так и в электронном виде. Он обратил внимание на то, что информационное пространство токсично, и библиотека - гарантия предоставления достоверной информации. Установлено, что индивид тратит в интернете на просмотр одной страницы в среднем 56 секунд, в течение которых библиотеке предстоит дать ему максимум полных и точных сведений.

В. В. Дуда представил новую схему действий Национальной электронной библиотеки (НЭБ), в соответствии с которой отбором изданий, поступающих по обязательному экземпляру, займутся специальные экспертные советы. Основной массив книг и периодических изданий будет предоставляться читателям за счет государства, для чего будут отслеживаться и оплачиваться каждое посещение и его длительность, а за пользование редкоспрашиваемой литературой придется платить читателям. В перспективе к этому процессу предполагается привлечь искусственный интеллект.

«Интересы молодежи в области искусства и культуры: возможности цифровых технологий» - тема доклада директора Российской государственной библиотеки для молодежи И. Б. Михновой. Эта библиотека работает на высоком уровне. Ежедневно ее посещают около 700 читателей. Библиотека видит свою миссию в обеспечении условий для самообразования, самопознания, самореализации и саморазвития молодежи. На это нацелены все библиотечные мероприятия, которые ориентированы на широкий круг разновозрастного населения.

Библиотека стала таким местом, куда хочется прийти, как говорится, по поводу и без. Здесь можно пользоваться документами или их 
фрагментами на любых носителях и устройствах; смотреть, слушать, музицировать, рисовать - причем как самостоятельно, так и коллективно, не мешая при этом остальным посетителям. К услугам пользователей - специализированные залы, кабинеты, лаборатории, студии, где можно зафиксировать процесс и результат собственного творчества. Библиотека создает и собственные документные ресурсы в виде подкастов (их уже более 40). Отдельное направление работы - помощь незрячим читателям в раскрытии их возможностей.

С 2015 г. многими электронными документами из фонда можно пользоваться дистанционно, из своего личного кабинета. Вне библиотечных стен желающим доступны видеолекторий, вебинары, подкасты, видеотрансляции. При этом адаптацию молодежи к цифровым технологиям библиотека рассматривает как средство, но отнюдь не как цель своей деятельности.

И. П. Тикунова, начальник Управления научной и методической деятельности - заведующая Центром по исследованию проблем развития библиотек в информационном обществе РГБ, выступила с докладом «Научно-информационная деятельность библиотек в сфере культуры и искусства: результаты мониторинга». От 50 проанкетированных крупнейших библиотек страны РГБ получила сведения о постановке информационной работы в сфере культуры и искусств. Специальные службы этого профиля имеют 44\% библиотек, в остальных такая деятельность возложена (по убывающей) на библиографические, методические, искусствоведческие, краеведческие отделы; в незначительной части библиотек это направление не выделено среди других направлений работы.

Около 30 библиотек ведут специализированные фонды литературы по культуре и искусству, отдельно - по библиотечному делу. Больше половины таких фондов доступны в интернете. Из форм информирования востребованы: ДОР (дифференцированное обслуживание руководителей) - в 22 библиотеках, ИРИ (избирательное распространение информации) - в 40; система «запрос - ответ» - в 42 библиотеках; используются и другие формы.

Доступ организован преимущественно через страницы в соцсетях. Реже практикуется информирование посредством собственных библиотечных сайтов; 4 библиотеки ведут специальные сайты. Наиболее 
популярны среди читателей выставки новых поступлений, дни информации и дни специалиста.

Многие годы, еще со времен активной деятельности Г. Ф. Гордукаловой (1950-2015), основоположницы вебометрического анализа, им углубленно занимается Санкт-Петербургский государственный институт культуры. С докладом «Вебометрический портрет театральных сайтов» выступила доцент этого вуза О. А. Александрова. Анализ сайтов проведен по нескольким параметрам: количество посетителей, интересующие их источники, полнота удовлетворения запросов. Проанализированы возможности наиболее популярных сайтов - «Театр» и «Театрал». Автор предложила более оперативно отслеживать новые направления в этом виде искусства, разнообразить формы контента, изучать запросы читателей в разных, а не только в давно известных аспектах.

Помимо пленарных, прозвучали доклады на секциях «Тенденции цифровизации информационной деятельности в сфере культуры», «Информационный потенциал организаций культуры в реализации государственной культурной политики», специальном заседании «Год театра в библиотеке» (организовано Российской государственной библиотекой искусств), круглом столе «Национальная библиотека как центр информации по культуре и искусству».

Отметим некоторые из представленных материалов.

На заседании круглого стола И. П. Тикунова представила доклад «Российская государственная библиотека в информационном контексте развития сферы культуры». Она рассказала о хранящихся в РГБ крупнейших специализированных подфондах литературы по культуре и искусству (1,5 млн ед. хр. изоизданий, более 420 тыс. нотных изданий и звукозаписей, 186 тыс. документов по библиотековедению, библиографоведению и книговедению и т.д.). Кроме того, в РГБ стремительно увеличиваются подфонды электронных изданий: 15,6 тыс. музыкальных сочинений практически всех времен и народов, жанров и форм, вся русская музыка и наиболее значительные произведения мирового репертуара); 6 тыс. плакатов, гравюр, русского лубка, открыток, фотографий и других изобразительных материалов. 
РГБ осуществляет индивидуальное информирование по вопросам культуры и искусства в режиме «запрос-ответ» и массовое информирование через свои сайты - официальный и тематические. Как общероссийский информационный центр по культуре и искусству РГБ способствует формированию современной информационной среды, участвует в организации единого информационного пространства России, в том числе в электронной среде, культивирует условия, обеспечивающие релевантный поиск, а главное - возможность доступа к необходимой информации.

Участники круглого стола поделились опытом постановки информации в сферах культуры и искусства.

О состоянии библиографических ресурсов национальных библиотек СНГ по проблемам культуры за 2015-2019 гг. рассказали заведующий научно-исследовательским отделом библиографии РГБ Г. Л. Левин и главный библиограф того же отдела Л. В. Жукова.

А. Н. Андреева (доклад "Обслуживание спещиалистов по культуре и искусству в Российской национальной библиотеке»), заведующая группой Информационно-библиографического отдела РНБ, сообщила, что такое специализированное обслуживание в РНБ ведет начало с 1811 г., когда Императорская публичная библиотека начала формировать свой фонд, включая в него в том числе и гравюры, а с 1813 г. обязательный экземпляр распространился и на гравированные издания. В 1850 г. было образовано Отделение изящных искусств и технологий, которое через 100 лет стало крупнейшим в стране Отделом эстампов.

В электронном фонде РНБ представлено около 3 тыс. документов Отдела эстампов различной тематики. В рамках проекта «Книжные памятники» начата оцифровка русского лубка. БД по русской иконографии (более 12,5 тыс. записей) иллюстрирована: воспроизведены портреты или сюжеты с участием того или иного персонажа.

С 2004 г. действует виртуальная справочная служба «Спроси библиографа», и сейчас ее архив, в котором свыше 37 тыс. ответов, - один из активно используемых ресурсов. Однако основным видом библиографического обслуживания остается локальное - на отраслевых пунктах. Библиографы создают универсальные и тематические электронные ресурсы собственной генерации. Среди них достойна упоминания серия путеводителей по справочным и библиографическим ресурсам. 
Общую характеристику профильных документных фондов по театральной проблематике, с которыми работают региональные библиотеки страны, представила ведущий научный сотрудник РГБ М. Л. Сухотина. В поле ее зрения попали 142 БД, отражающие вопросы театральных постановок, изоматериалы, календари знаменательных дат и тематические библиографические пособия. Как лучшие в этом отношении были отмечены Новосибирская и Курганская ОНБ. Положительно оценены также Краснодарская, Псковская, Орловская, Оренбургская, Омская, Томская, Рязанская областные библиотеки.

Начальник отдела ценных и редких книг Новосибирской государственной областной научной библиотеки С. М. Ермоленко поделился опытом создания интерактивной географической карты в Музее книги.

Т. Р. Горшкова, главный библиограф РГБ, охарактеризовала специфику электронного каталога по музыке РГБ. Он интересен тем, что позволяет по многоаспектным ключевым словам переходить сразу к полнотекстовым документам. Автор видит перспективу развития библиографических описаний в этом ЭК в том, чтобы добавить к поисковым признакам слова, встречающиеся между нотных строк, - это расширило бы возможности удовлетворения особо сложных запросов.

Старший научный сотрудник БЕН РАН А. А. Ивановский в докладе «Избирательное информирование пользователей на основе отечественных ресурсов по гуманитарным наукам: задачи и вызовы» отметил, что при осуществлении ИРИ библиотекой найдены возможности сопрягать собственные фонды с внешними, включая зарубежные. Докладчик подчеркнул необходимость усовершенствовать отечественную elibrary в соответствии с параметрами аналогичных международных систем, сделать отечественные поисковые системы более гибкими и согласованными с иностранными.

О расширении творческого потенциала Архангельской областной научной библиотеки им. Н. А. Добролюбова, привлекшей к совместной работе театральную общественность своего и других городов, рассказала заведующая сектором информации по культуре и искусству этой библиотеки Н. В. Попова в докладе ""ЧтиТеатр!", или Играючи о книгах». Изготавливаемые библиотекой видеоролики о театральной жизни 
Архангельска и других городов, сопровождаемые библиографическими списками и обзорами, вызывают живой интерес населения и многотысячные обращения к этим уникальным материалам.

Картину создания и использования краеведческих документных ресурсов по культуре в одном из малых городов российской глубинки, Губкине Белгородской области, представила Т. И. Извекова - директор Централизованной библиотечной системы № 1. Среди малых городов Губкин 19 раз занимал первое место по постановке культурной работы с населением. Из их инноваций последнего времени обращает на себя внимание практика создания оригинальных аудиокниг для слепых «Услышать живопись».

О большой программе мероприятий, разработанных и успешно проведенных Российской государственной библиотекой искусств, рассказали ее сотрудники - В.В.Мурзинова, И. Б. Титунова, С. Н. Чевычалова, О. Н. Початкина, Г. М. Чижова, Е. Е. Шумянцева.

Старший научный сотрудник Президентской библиотеки им. Б. Н. Ельцина А.В. Воронович осветил вопросы формирования и представления к Году театра в России соответствующего цифрового подфонда этой библиотеки.

Насыщенной была работа секции «Информационный потенциал организаций культуры в реализации государственной культурной политики». Выступавшие - директор Курганской ОУНБ им. А. К. Югова Н. А. Катайцева, заведующая сектором информации по культуре и искусству Дворца книги - Ульяновской ОНБ им. В. И. Ленина Л. А. Утина, заведующая информационно-справочным отделом Национальной библиотеки Республики Карелия Д. А. Зулкарнеева, директор Иркутского областного учебно-методического центра культуры и искусства «Байкал» Т. М. Киселева, организатор социокультурных проектов «МАСТАРТ» (Москва) Т. В. Хазова, ведущий научный сотрудник РГБ E. В. Губина - поделились богатым и разнообразным опытом работы с фондами литературы по искусству.

Обмен мнениями и накопленным опытом трех национальных библиотек России - РГБ, РНБ, Президентской библиотеки им. Б. Н. Ельцина, а также специалистов национальных библиотек других государств Содружества, показал, что эти библиотеки используют совре- 
менные технологии сбора, аналитической обработки и распространения информации, благодаря чему являются для своих стран значимыми информационными центрами по культуре.

Конференция была своего рода смотром достигнутого в обслуживании населения литературой по культуре и искусству. Руководителям библиотек и служб информации ее участники рекомендовали:

содействовать цифровизации деятельности, направленной на формирование общедоступных ресурсов по культуре и искусству, организацию информационного обслуживания в режиме 7/24 через интернет;

активизировать участие в совместных проектах, включая международные;

при создании документных ресурсов и методических материалов неукоснительно соблюдать авторское право.

От РГБ ожидается продолжение научно-методического и информационного обеспечения.

Ценно, что по итогам таких мероприятий РГБ издает сборники материалов. Последний из них вышел в 2018 г. (Библиотеки в информационном обеспечении реализации государственной культурной политики : материалы $X$ Всерос. совещания служб информ. по культуре и искусству. Москва 3-4 окт. 2017 г. / Рос. гос. б-ка. Москва : Пашков дом, 2018. - 218 с.). Он включает в себя 25 обширных публикаций и много дополнительных материалов, которые могут служить подспорьем в постановке и успешном проведении рассматриваемого направления деятельности.

\section{Информация об авторе / Information about the author}

Столяров Юрий Николаевич - доктор пед. наук, профессор, главный научный сотрудник Научного и издательского центра «Наука» РАН и Российской государственной библиотеки, заслуженный работник культуры РФ, Москва, Россия yn100@narod.ru
Yury N. Stolyarov - Dr. Sc. (Pedagogy), Professor, Leading Researcher, Science and Publishing Center "Nauka" of Russian Academy of Sciences, Russian State Library, Moscow, Russia

yn100@narod.ru 